\title{
The Renin-Angiotensin System Regulates Neurodegeneration in a Mouse Model of Optic Neuritis
}

\author{
Xiaoli Guo, Kazuhiko Namekata, Atsuko Kimura, Chikako Harada, and Takayuki Harada
}

From the Visual Research Project, Tokyo Metropolitan Institute of Medical Science, Tokyo, Japan

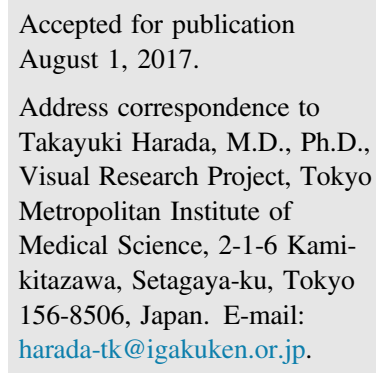

Address correspondence to Takayuki Harada, M.D., Ph.D., Visual Research Project, Tokyo Metropolitan Institute of Medical Science, 2-1-6 Kamikitazawa, Setagaya-ku, Tokyo 156-8506, Japan. E-mail: harada-tk@igakuken.or.jp.

\begin{abstract}
The major role of the renin-angiotensin system (RAS), including that of angiotensin II (Ang II), the principal effector molecule, in the cardiovascular system is well known. Increasing evidence suggests that the RAS also plays a role in the development of autoimmune diseases. Optic neuritis (ie, inflammation of the optic nerve, with retinal ganglion cell loss) is strongly associated with multiple sclerosis. We investigated the effects of candesartan, an Ang II receptor antagonist, on optic neuritis in experimental autoimmune encephalomyelitis (EAE), an animal model of multiple sclerosis. The Ang II concentration was increased in the early phase of EAE. Oral administration of candesartan markedly attenuated demyelination of the optic nerve and spinal cord and reduced retinal ganglion cell loss and visual impairment in mice with EAE. In vitro analyses revealed that Ang II up-regulated the expression of Toll-like receptor (TLR)-4 in astrocytes via the NF- $\kappa$ B pathway. In addition, Ang II treatment enhanced lipopolysaccharide-induced production of monocyte chemoattractant protein 1 in astrocytes, and pretreatment with candesartan or SN50, an NF- $\kappa$ B inhibitor, suppressed the effects of Ang II. The novel pathway of RAS-NF- $\mathrm{B}$-TLR4 in glial cells identified in the present study may be a valid therapeutic target for neurodegeneration in neuroinflammatory diseases. (Am J Pathol 2017, 187: 2876-2885; https://doi.org/10.1016/j.ajpath.2017.08.012)
\end{abstract}

Optic neuritis refers to inflammation of the optic nerve, with retinal ganglion cell (RGC) loss. ${ }^{1-3}$ An epidemiologic study in the United States estimated that the annual incidence rate of optic neuritis was 5 per 100,000 population. ${ }^{4}$ There is a strong association between optic neuritis and multiple sclerosis (MS), an acute inflammatory demyelinating syndrome of the central nervous system (CNS) characterized by progressive immune-mediated destruction of the myelin sheath and accumulated neurological disability. ${ }^{1}$ Optic neuritis can result in severe, irreversible visual loss, especially the optic-spinal form of MS or neuromyelitis optica. ${ }^{5}$ Thus, much attention is focused on finding a treatment for this disease that can restore visual function.

The major role of the renin-angiotensin system (RAS) in the cardiovascular system is well known. ${ }^{6}$ Renin, a proteolytic enzyme primarily released by the kidneys, cleaves angiotensinogen to angiotensin I (Ang I). Ang I is further processed by angiotensin-converting enzymes (ACEs), including ACE2, to different angiotensin cleavage products. ${ }^{6}$ Among these, angiotensin II (Ang II) is the principal effector molecule of the RAS, acting on its target cells, mainly via the Ang II type 1 receptor (AT1R). ${ }^{7}$ Currently, Ang II receptor antagonists and ACE inhibitors are used as prescribed drugs to treat high blood pressure. ${ }^{8}$ In addition, recent studies implicated the RAS in the development of autoimmune diseases..$^{9-12}$ When components of the RAS, such as ACEs and Ang II, were expressed in the immune system in experimental autoimmune encephalomyelitis (EAE), an experimental animal model of MS, inhibition of these components produced in different steps of the RAS system all markedly ameliorated the course of EAE. $^{9-11}$ Moreover, Ang II has been identified as a

Supported by the Japan Society for the Promotion of Science grants-inaid for scientific research JP16K07076 (X.G.), JP16K08635 (K.N.), JP17K07123 (A.K.), JP16K11308 (C.H.), and JP15H04999 (T.H.) and the Takeda Science Foundation (T.H.).

Disclosures: None declared. 
paracrine mediator, which sustains inflammation in the CNS by up-regulating transforming growth factor (TGF)- $\beta .^{13}$ AT1Rs were reported to be primarily expressed in CNSresident cells during EAE. ${ }^{13}$ In vitro, astrocytes and microglia responded to Ang II treatment by inducing TGF- $\beta$ expression via a pathway involving TGF- $\beta$-activating protease thrombospondin- $1 .{ }^{13}$ When TGF- $\beta$ up-regulation in astrocytes and microglia during EAE was blocked using candesartan, an inhibitor of AT1R, paralysis and blunted lymphocyte infiltration into the CNS were ameliorated. ${ }^{13}$ Thus, the RAS may be a potential new target for optic neuritis therapy.

Toll-like receptors (TLRs) are expressed in many cell types, and their expression levels are altered under pathologic conditions. ${ }^{14-16}$ For example, the expression of TLR3 and TLR4 was up-regulated in patients with MS, and the expression of TLR2, TLR4, and TLR9 was up-regulated in the spinal cord of mice with EAE. ${ }^{17,18}$ Consistent with these reports, in vivo treatment with specific TLR ligands exacerbated EAE, whereas targeted disruption of selected TLRs prevented EAE. ${ }^{17,19-21}$ These results suggest that TLRs have critical roles in MS and EAE. ${ }^{22}$ However, the molecular mechanisms that regulate TLRs during inflammatory autoimmune diseases remain elusive. One study reported that Ang II up-regulated TLR4 mRNA and protein expression in mouse mesangial cells and that this effect was mediated through AT1R. ${ }^{23}$ We previously reported that Ang II stimulated TLR4 and lipopolysaccharide (LPS)-induced production of inducible nitric oxide synthase (iNOS) in cultured retinal Müller glial cells and that this effect was suppressed by candesartan. ${ }^{24}$ Moreover, candesartan exerted neuroprotective effects on RGC loss in a mouse model of normal tension glaucoma by suppressing TLR4 and LPSinduced iNOS expression in the retina. ${ }^{24}$ The potential role of Ang II in modulating the expression of TLRs during EAE remains to be explored. In the present study, we investigated the effects of candesartan on optic neuritis and demonstrated an association between the RAS and innate immunity during EAE.

\section{Materials and Methods}

\section{Animals}

Female C57 BL/6J mice (CLEA Japan, Tokyo, Japan) were used in the experiments in accordance with the Tokyo Metropolitan Institute of Medical Science Guidelines for the Care and Use of Animals. The mice were aged 6 to 8 weeks at the time of immunization. All the experiments were approved by the Tokyo Metropolitan Institute of Medical Science.

\section{Reagents}

CV-11974 and its prodrug candesartan cilexetil were gifts from Takeda Pharmaceutical Co., Ltd., Osaka, Japan. ${ }^{25}$
CV-11974 was used for in vitro assays, and candesartan cilexetil was used for in vivo experiments. For the sake of simplicity, throughout the article, candesartan refers to candesartan cilexetil. Ang II was purchased from Sigma (St. Louis, MO), and SN50 was purchased from Calbiochem (Rotkreuz, Switzerland).

Induction of $E A E$, Administration of Candesartan, and Clinical Scoring

All the experiments were conducted according to the experimental timeline summarized in Figure 1, A and B. EAE was induced in mice using the myelin oligodendrocyte glycoprotein $(\mathrm{MOG})_{35-55}$ peptide (MEVGWYRSPFSRVVHLYRNGK), as previously reported. ${ }^{26}$ Briefly, the mice received s.c. injections with $100 \mu \mathrm{g}$ of $\mathrm{MOG}_{35-55}$ mixed with $500 \mu \mathrm{g}$ of heat-killed Mycobacterium tuberculosis H37RA (Difco, Schwechat, Austria) emulsified in complete Freund's adjuvant. Each mouse also received i.p. injections of $500 \mathrm{ng}$ of pertussis toxin (Seikagaku, Tokyo, Japan) immediately and 48 hours after immunization. The mice were divided into two groups (Figure 1, A and B). In the blood sampling group (Figure 1A), to collect enough blood for measuring the concentrations of Ang II using an enzyme-linked immunosorbent assay, the mice were anesthetized with sodium thiopental, the chest cavity was opened, and blood was drawn directly from the heart on day 7,10 , and 25 after MOG immunization. The mice were euthanized immediately after the procedure. Serum Ang II concentrations were measured using an enzyme-linked immunosorbent assay kit (E90005Mu, Uscn Life Science Inc., Wuhan, China). In the treatment group (Figure 1B), MOG-immunized mice were treated with candesartan $(10 \mathrm{mg} / \mathrm{kg}$ in $0.5 \%$ carboxymethyl cellulose) or vehicle ( $0.5 \%$ carboxymethyl cellulose) by oral gavage once daily throughout the whole experimental period. Clinical signs were scored daily as follows: 0 , no clinical signs; 1, loss of tail tonicity; 2, flaccid tail; 3, impairment of righting reflex; 4, partial hind limb paralysis; 5, complete hind limb paralysis; 6 , partial body paralysis; 7 , partial forelimb paralysis; 8 , complete forelimb paralysis or moribund; and 9, death.

\section{Histologic Analysis}

On day 25 after immunization, the mice were perfused with Zamboni's fixative (2\% paraformaldehyde and $15 \%$ picric acid in $0.1 \mathrm{~mol} / \mathrm{L}$ phosphate buffer; Sigma), and eyes, optic nerves, and lumbar spinal cords were removed. ${ }^{27,28}$ The eyes were postfixed in 3\% glutaraldehyde solution (3\% glutaraldehyde, $9 \%$ formaldehyde, $37.5 \%$ ethanol, and $12.5 \%$ acetic acid in distilled water) for 2 hours. Paraffin-embedded retinal sections $7-\mu \mathrm{m}$ thick were cut through the optic nerve and stained with hematoxylin and eosin. To quantify the number of neurons in the ganglion cell layer of the retina, cells were counted from one ora serrata through the optic nerve to the 


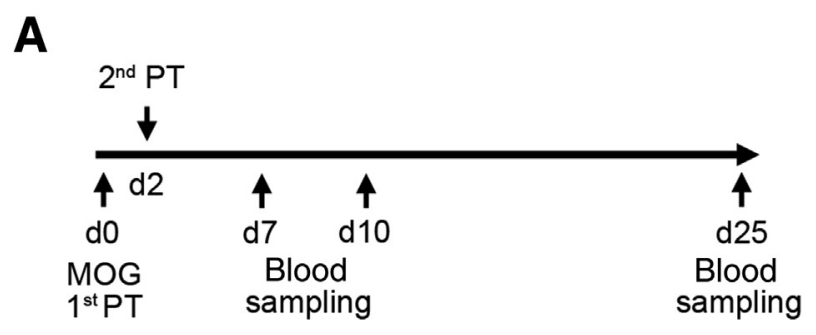

B
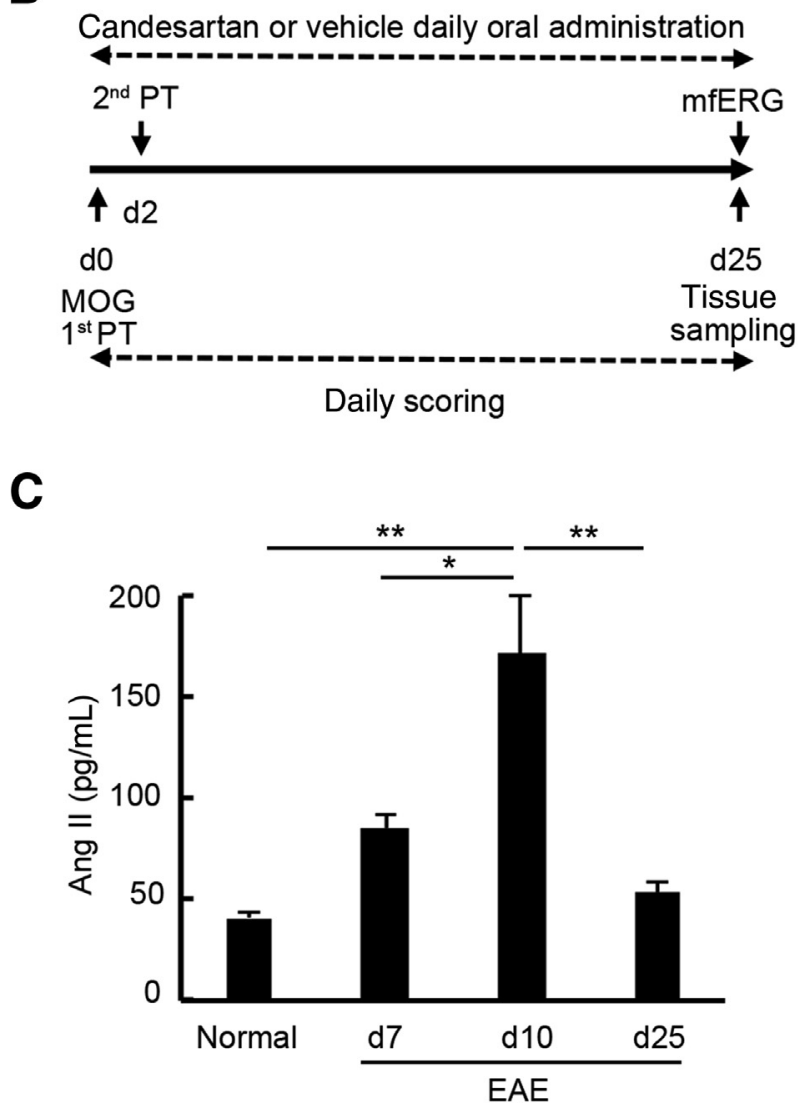

Figure 1 Experimental timeline and angiotensin II (Ang II) concentration in the serum of mice with experimental autoimmune encephalomyelitis (EAE). In the experimental protocols, the mice were divided into two groups. A: In the blood sampling group, concentrations of Ang II in the serum were measured on days 7,10 , and 25 after myelin oligodendrocyte glycoprotein (MOG) immunization. B: In the treatment group, candesartan or vehicle was administrated daily until the mice were sacrificed on day 25. Multifocal electroretinograms (mfERGs) were recorded before sampling. C: Ang II concentrations in the serum of mice with EAE. Data are expressed as means \pm SEM. $n=5$ (C). ${ }^{*} P<0.05,{ }^{*} P<0.01$. d, day; PT, pertussis toxin.

other ora serrata. ${ }^{28,29}$ Optic nerves and lumbar spinal cords were postfixed in Zamboni's fixative overnight. Paraffinembedded sections that were $7-\mu \mathrm{m}$ thick were stained with Luxol fast blue followed by hematoxylin and eosin staining.

\section{Immunohistochemistry}

Paraffin-embedded sections (7- $\mu \mathrm{m}$ thick) were examined using the following primary antibodies: mouse anti-NF200
(1:400; Sigma), mouse anti-glial fibrillary acidic protein (GFAP) $(50 \mu \mathrm{g} / \mathrm{mL}$; Progen, Heidelberg, Germany), goat anti-iba1 (1:400; Abcam, Cambridge, England), goat antiTLR4 (2 $\mu \mathrm{g} / \mathrm{mL}$; sc-16240; Santa Cruz Biotechnology, Santa Cruz, CA), and rabbit anti-NF-кB p65 (1:500; catalog number 8242; Cell Signaling, Danvers, MA). The antibodies against TLR-4 ${ }^{18,24,30,31}$ and NF- $\kappa \mathrm{B}^{32,33}$ have been widely used and described elsewhere. Stained sections were examined using a microscope (BX51; Olympus Corporation, Tokyo, Japan) connected to a DP70 camera (Olympus). Images were processed and viewed using DP manager software version 2.2.1.195 (Olympus). Quantitative analysis of the stained region was performed using ImageJ software version 1.46r (NIH, Bethesda, MD; http://imagej.nih.gov/ij).

\section{Multifocal Electroretinogram Recordings}

The mice were anesthetized by an i.p. injection of sodium pentobarbital $(87.5 \mathrm{mg} / \mathrm{kg})$. The pupils were dilated with $0.5 \%$ phenylephrine hydrochloride and $0.5 \%$ tropicamide. Multifocal electroretinograms were recorded using a VERIS 6.0 system (Electro-Diagnostic Imaging, Redwood City, CA). The visual stimulus consisted of seven hexagonal areas scaled with eccentricity. The stimulus array was displayed on a high-resolution black and white monitor, with a frame rate of $100 \mathrm{~Hz}$. The second-order kernel of multifocal electroretinograms, which is a sensitive indicator of inner retinal dysfunction, was measured as previously reported. ${ }^{18,28}$

\section{Cell Culture}

Primary astrocytes were obtained as previously reported..$^{18}$ After two passages, the astrocytes were plated according to their intended purposes. The cells were pretreated with or without CV-11974 or SN50 $(50 \mu \mathrm{g} / \mathrm{mL})$ for 45 minutes, stimulated with Ang II for 6 or 24 hours, and subjected to quantitative PCR or immunoblot analysis. In the preliminary experiments, we used three concentrations of CV-11974 (100 $\mathrm{nmol} / \mathrm{L}, 1 \mu \mathrm{mol} / \mathrm{L}$, and $10 \mu \mathrm{mol} / \mathrm{L}$ ) and found that $10 \mu \mathrm{mol} / \mathrm{L}$ of CV-11974 was the most effective. For Ang II, we tested two concentrations $(10 \mathrm{nmol} / \mathrm{L}$ and $100 \mathrm{nmol} / \mathrm{L})$ but found no marked difference between the two concentrations. Thus, we selected $10 \mu \mathrm{mol} / \mathrm{L}$ for CV-11974 and $10 \mathrm{nmol} / \mathrm{L}$ for Ang II for the whole study. To investigate the effects of Ang II on the production of monocyte chemotactic protein (MCP)-1 in astrocytes, the cells were pretreated with CV-11974 (10 $\mu \mathrm{mol} / \mathrm{L})$ and SN50 $(50 \mu \mathrm{g} / \mathrm{mL})$, followed by Ang II stimulation for 24 hours, and then stimulated with LPS $(2 \mathrm{ng} / \mathrm{mL})$ for 24 hours. The levels of secreted MCP-1 in the culture medium of astrocytes were determined by an enzyme-linked immunosorbent assay (R\&D Systems, Minneapolis, MN).

\section{Real-Time Quantitative PCR}

Real-time quantitative PCR was performed using an ABI 7500 fast real-time PCR system (Applied Biosystems, 
Foster City, CA) with SYBR Green PCR Master Mix (Applied Biosystems), as previously reported. ${ }^{34}$ cDNA reverse transcribed from total RNA was amplified using primers specific for TLR2 (sense: 5'-CCCACTTCAGGCTCTTTGAC-3': antisense: $5^{\prime}$-GCCACTCCAGGTAGGTCTTG-3'), TLR3 (sense: 5'-GTGCATCGGATTCTTGGTTT-3': antisense: $5^{\prime}$-TTCCCAGACCCAGTCTCTGT- ${ }^{\prime}$ ), TLR4 (sense: 5'-GCCGGAAGGTTATTGTGGTA-3': antisense: $5^{\prime}$-TGCCATGTTTGAGCAATCTC-3'), TLR9 (sense: $5^{\prime}$-CAGCCCTGACTAGGGACAAC-3': antisense: 5'-CGGGAACCAGACATGAAGAT-3'), glyceraldehyde-3-phosphate dehydrogenase (sense: $5^{\prime}$-TGCACCACCAACTGCTTAG-3': antisense: $5^{\prime}$-GGATGCAGGGATGATGTTC- ${ }^{\prime}$ ). Data were normalized to the level of glyceraldehyde-3-phosphate dehydrogenase mRNA.

\section{Immunoblot Analysis}

Immunoblotting was performed as previously reported. ${ }^{27}$ Cell culture samples were separated by SDS-PAGE and subsequently transferred to an Immobilon-P filter (Millipore, Milan, Italy). Membranes were incubated with an antibody against TLR4 (1:500; Santa Cruz Biotechnology), NF-кB p65 (1:1000, Cell Signaling), Histone H3 (1:1000; Cell Signaling), or actin (1:1000; BD Biosciences). For quantification of TLR4 or NF- $\kappa \mathrm{B}$ p65 expression levels, band intensities were analyzed using ImageJ software version 1.46r and normalized to the expression levels of actin or Histone $\mathrm{H} 3$.

\section{Statistical Analysis}

Data are presented as means \pm SEM. A one-way analysis of variance, followed by the Tukey-Kramer post hoc test or $t$-test was used for the statistical analyses. $P<0.05$ was regarded as statistically significant. JMP version 12.2.0 (SAS Institute Inc., Cary, NC) was used for the statistical analyses.

\section{Results}

Candesartan Ameliorated Optic Neuritis and Retinal Degeneration in Mice with $\mathrm{EAE}$

Previous research revealed the involvement of the RAS in oxidative stress-induced RGC death in vitro and in vivo. ${ }^{24,35}$ To determine whether the RAS was involved in the pathogenesis of EAE, we first examined Ang II concentrations in the serum of mice with MOG-induced EAE at several time points (Figure 1A). Ang II concentrations in mice with EAE were significantly increased compared with those of healthy mice on day 10 after MOG immunization when the mice started to exhibit EAE signs (Figure 1C). On the other hand, by day 25, Ang II concentrations in mice with EAE were comparable to those of healthy mice when EAE mice were in the chronic phase (Figure 1C). These results suggest that the RAS has an important role during the development of EAE.

We then examined the effects of an orally active Ang II receptor antagonist candesartan on MOG-induced EAE in mice (Figure 1B). Histopathologic analysis of the optic nerves on day 25 revealed inflammatory cells and distinctive demyelination in optic nerve lesions in the vehicle-treated mice, whereas these findings were almost absent in the candesartan-treated mice with EAE (Figure 2A). These findings are consistent with those of previous reports. ${ }^{18,28}$ Furthermore, as revealed by NF200 staining, the rate of axonal survival was higher in the candesartan-treated mice with EAE, and the rate of GFAP-positive astrocytes and iba1-positive microglial cells were lower in this group (Figure 2B), indicating that candesartan administration ameliorated the severity of optic neuritis.

We next examined the neuroprotective effects of candesartan in the mice with EAE. In the vehicle-treated mice, the number of surviving neurons in the ganglion cell layer was significantly reduced, whereas candesartan treatment prevented cell loss (Figure 3, A and C). To determine whether the observed effects of candesartan on RGCs and optic nerves were functionally significant, we analyzed visual function using multifocal electroretinography, which is a vital tool for substantiating histologic observations of physiologic phenomena in the retina. ${ }^{18,36,37}$ The response topography revealed impaired visual function in the vehicletreated mice with EAE in all visual fields, and visual function was partially improved by the candesartan treatment (Figure 3, B and C). These results suggested that the neuroprotective effects of candesartan in the mice with EAE were functionally significant.

As shown by the clinical scores, candesartan treatment significantly reduced the severity of EAE and delayed disease onset (Figure 4A), consistent with the findings of a previous report. ${ }^{13}$ However, it had no effects on the incidence of EAE (Figure 4B). Taken together, these data indicate that inhibition of Ang II exerts effects at histologic and functional levels, attenuating not only inflammation in spinal cords but also EAE-induced optic neuritis and RGC degeneration.

\section{Candesartan Suppressed TLR4 Expression in Mice with EAE}

We previously reported that Ang II increased TLR4 expression in retinal Müller glial cells in vitro and that candesartan treatment provided protection against RGC loss in a mouse model of normal tension glaucoma by inhibiting the TLR4 pathway. ${ }^{24}$ Previous studies found that upregulated expression of TLR4 was involved in EAE progression. ${ }^{17,18}$ To investigate whether Ang II increased TLR4 expression in astrocytes and whether candesartan suppressed this effect, we stimulated primary cultured astrocytes, which express AT1R and contribute to disease progression in MS and EAE, ${ }^{13}$ with Ang II. The real-time 


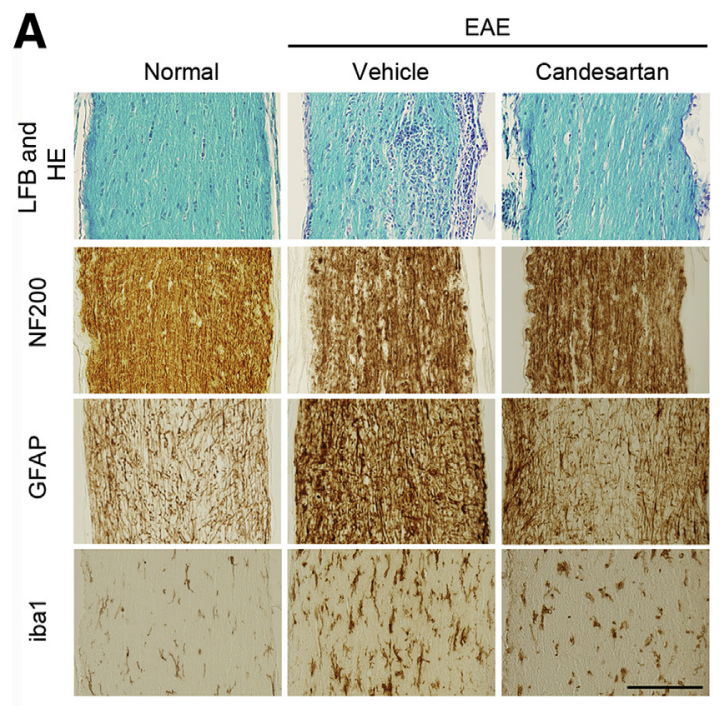

\section{B}
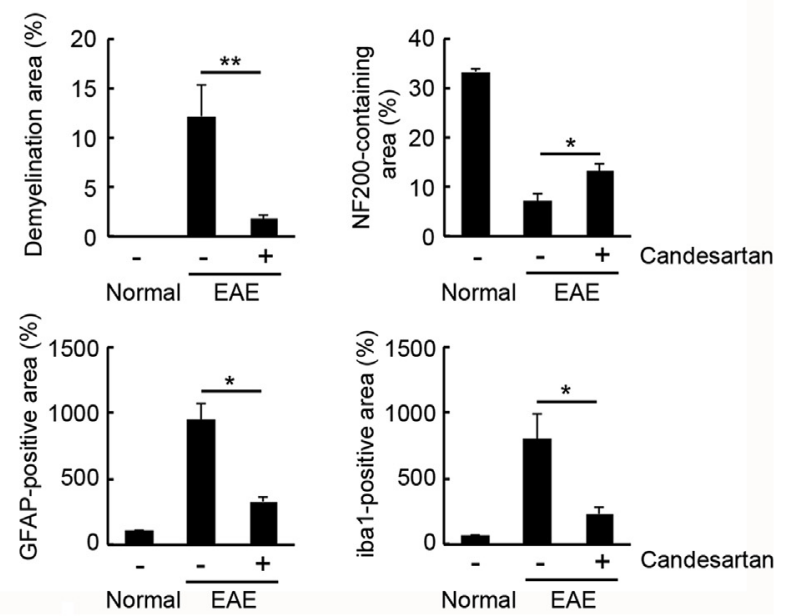

Figure 2 Candesartan suppressed demyelination, axonal degeneration, and neuroinflammation in optic nerves during experimental autoimmune encephalomyelitis (EAE). A: Optic nerves were stained with Luxol fast blue (LFB), hematoxylin and eosin (H\&E), anti-NF200, anti-glial fibrillary acidic protein (GFAP), or anti-iba1 antibody. B: Quantitative analysis of demyelination, axonal degeneration, GFAP-positive areas, and iba1-positive areas in the optic nerves. Data are expressed means \pm SEM. $n=7$ (B). ${ }^{*} P<0.05,{ }^{* *} P<0.01$. Scale bar $=110 \mu \mathrm{m}(\mathbf{A})$.

quantitative PCR analysis revealed that Ang II up-regulated mRNA expression levels of TLR4 but not those of TLR2, TLR3, or TLR9. Furthermore, pretreatment with CV-11974, an in vitro antagonist of Ang II, completely abrogated this increase (Figure 5A). A Western blot analysis revealed similar findings (Figure 5B).

We next examined TLR4 mRNA expression in the spinal cord of mice with EAE and found that candesartan treatment suppressed EAE-induced up-regulation of TLR4 (Figure 6A). Moreover, double-labeling immunohistochemistry of TLR4 and GFAP revealed that TLR4 expression in astrocytes was significantly reduced in the candesartan-treated mice with EAE (Figure 6, B and C). Taken together, these data suggest that candesartan improves optic neuritis partially through the inhibition of innate immune responses in astrocytes.

\section{Ang II Increased TLR4 Expression via the NF- $\kappa B$ Pathway}

$N F-\kappa B$ is activated by TLR engagement and a variety of inflammatory signals. ${ }^{38}$ Because NF- $\kappa \mathrm{B}$ can affect the incidence and severity of EAE, we investigated whether $\mathrm{NF}-\kappa \mathrm{B}$ was involved in Ang II-induced TLR4 expression. The results indicated that the Ang II treatment significantly increased nuclear translocation of $\mathrm{NF}-\kappa \mathrm{B}$ in astrocytes in vitro and that pretreatment with CV-11974 or SN50, an inhibitor of NF- $\kappa \mathrm{B}$ nuclear translocation, suppressed the effects of Ang II (Figure 7A). Furthermore, preincubation with SN50 suppressed Ang II-induced up-regulation of TLR4 (Figure 7B). Double-labeling immunohistochemistry of NF- $\kappa \mathrm{B}$ and GFAP in the spinal cord revealed that astrocytes with nuclear $\mathrm{NF}-\kappa \mathrm{B}$ expression were significantly reduced in the candesartan-treated mice with EAE (Figure 7, C and D).
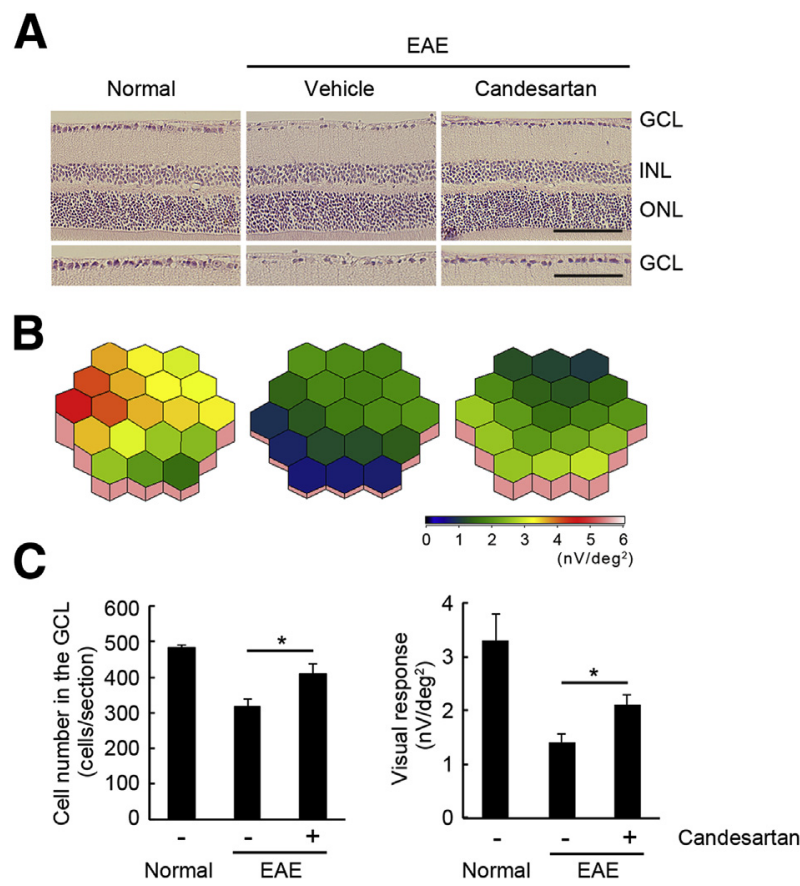

Figure 3 Candesartan ameliorated retinal ganglion cell loss and visual impairment induced by experimental autoimmune encephalomyelitis (EAE). A: Hematoxylin and eosin staining of representative retinal sections in healthy, vehicle, and candesartan-treated mice with EAE. B: Representative images of three-dimensional plots depicting averaged visual responses of the second-order kernel examined by a multifocal electroretinogram. The degree of retinal function is presented by the color bar. A higher score (red) indicates highly sensitive visual function, and a lower score (green) indicates retinal dysfunction. Values are given in nanovolts per square degree $\left(\mathrm{nV} / \mathrm{deg}^{2}\right)$. C: Quantitative analysis of cell numbers in the ganglion cell layer (GCL) (left panel) and visual response (right panel). Data are expressed as means \pm SEM. $n=4$ (C). ${ }^{*} P<0.05$. Scale bars: $100 \mu \mathrm{m}(\mathbf{A}$, top row); $70 \mu \mathrm{m}$ (A, bottom row). INL, inner nuclear layer; $0 \mathrm{NL}$, outer nuclear layer. 

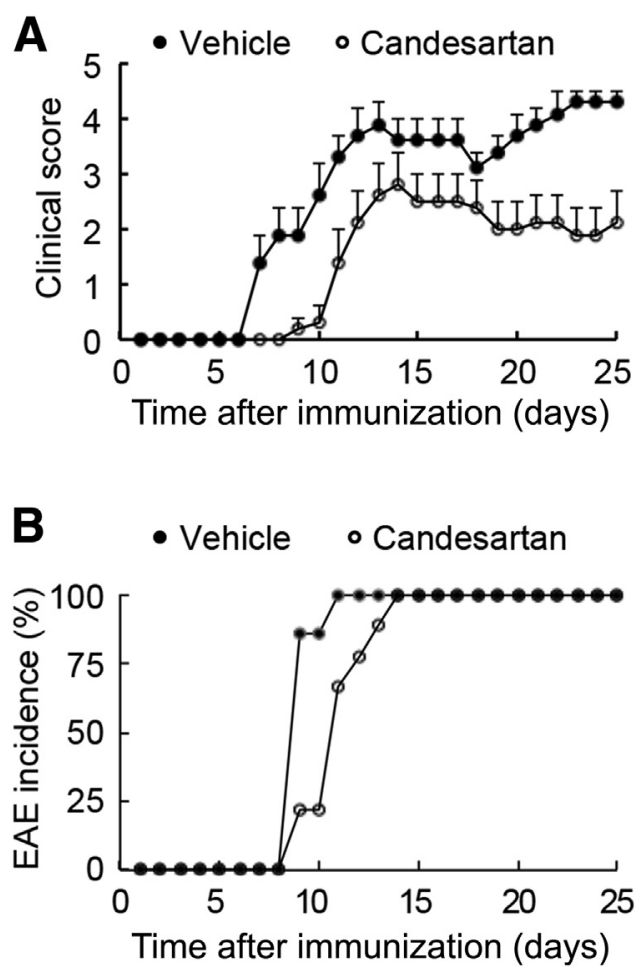

Figure 4 Effects of candesartan on the severity and incidence of experimental autoimmune encephalomyelitis (EAE). Clinical evaluation of EAE disease $(\mathbf{A})$ and the incidence of EAE (B) on day 25 in the mice treated with vehicle or candesartan. $n=15$ vehicle mice $(\mathbf{A}$ and $\mathbf{B}) ; n=7$ candesartan mice (A and $\mathbf{B})$.

We further investigated the functional significance of TLR4 up-regulation by Ang II in astrocytes. LPS-induced production of MCP-1 was significantly increased when astrocytes were pretreated with Ang II, but the addition of CV-11974 or SN50 suppressed this increase (Figure 7E), indicating that candesartan ameliorated the severity of EAE partially through the inhibition of chemokine expression in astrocytes.

\section{Discussion}

In the present study, we measured Ang II concentrations in serum and found that its concentration was significantly increased in the early phase of EAE in mice compared with that of healthy mice, pointing to an important role for the RAS during EAE. Circulating Ang II might act on immune cells, such as dendritic cells or T cells, to induce or increase the severity of EAE, whereas the Ang II receptor antagonist candesartan might attenuate EAE. To elucidate the role of the RAS in the CNS during EAE, further investigations of Ang II concentrations in cerebrospinal fluid, namely, concentrations of brain tissueparacrine Ang II, are required.

We found that candesartan ameliorated inflammationmediated degeneration in optic nerves and spinal cords. These findings are consistent with those of a previous report, which found that candesartan delayed the onset of MOGinduced EAE and attenuated disease severity. ${ }^{13}$ In addition, we found that Ang II up-regulated TLR4 expression in astrocytes via a NF- $\kappa \mathrm{B}$ pathway and enhanced LPS-induced chemokine release from astrocytes and that candesartan suppressed the effects of Ang II. A previous study reported that the Ang II receptor antagonist inhibited up-regulation of molecules, such as TGF- $\beta .^{13}$ TGF- $\beta$ is a multipotent cytokine, and its role is determined by the surrounding milieu. ${ }^{13}$ In the CNS, TGF- $\beta$ signaling is markedly up-regulated before and during the onset of EAE, creating a suitable environment for inflammation. ${ }^{39}$ Thus, inhibition of TGF- $\beta$ up-regulation in the CNS by candesartan leads to attenuated severity in mice with EAE. ${ }^{13}$ In addition, candesartan may inhibit neuroinflammation during optic neuritis by suppressing the activity of microglia, which have important roles in neuroinflammation. ${ }^{40}$ We previously reported that inhibition of microglial activation ameliorated the severity of the effects of

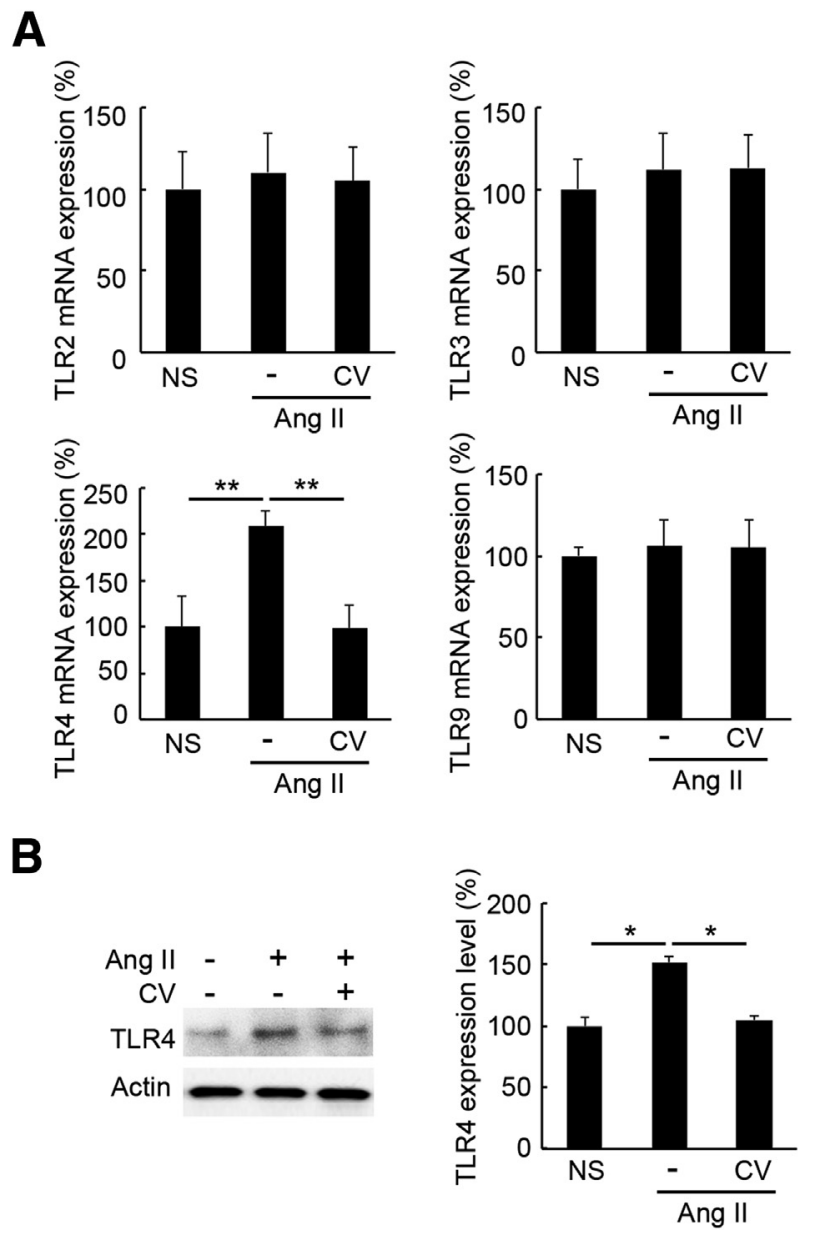

Figure 5 Expression levels of Toll-like receptors (TLRs) in astrocytes stimulated with angiotensin II (Ang II). A: Quantitative PCR analysis of TLR2, TLR3, TLR4, and TLR9 mRNA expression in astrocytes stimulated with Ang II for 6 hours after pretreatment with or without CV-11974 (CV) for 45 minutes. B: Immunoblot analysis of TLR4 in astrocytes stimulated with Ang II for 24 hours after pretreatment with or without CV for 45 minutes. Data are expressed as means \pm SEM for a representative experiment run in quadruplicate. ${ }^{*} P<0.05,{ }^{*} P<0.01$. NS, no stimulus. 


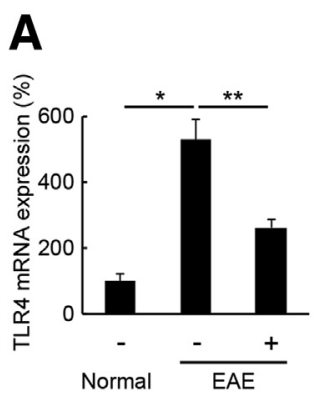

\section{B}
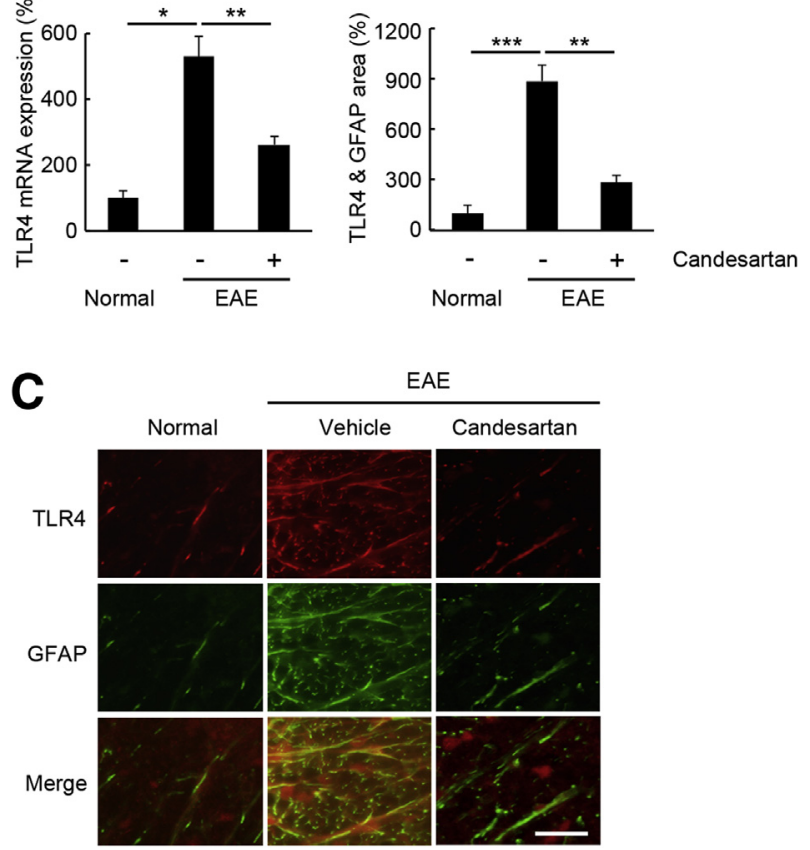

Figure 6 Candesartan suppressed up-regulation of Toll-like receptor (TLR)-4 in the spinal cords of mice with experimental autoimmune encephalomyelitis (EAE). A: Quantitative PCR analysis of TLR4 in the spinal cords of mice with EAE with or without candesartan treatment. B: Quantitative analysis of TLR4 and glial fibrillary acidic protein (GFAP) double-positive areas in C. C: Immunohistochemistry using antibodies for TLR4 (red) and GFAP (green) in the spinal cord of mice with EAE with or without candesartan treatment. Data are expressed as means \pm SEM. $n=4$ (A and $\mathbf{B})$. ${ }^{*} P<0.05,{ }^{* *} P<0.01$, and $* * * P<0.001$. Scale bar $=40 \mu \mathrm{m}$.

EAE on the spinal cord and optic nerves. ${ }^{18,34}$ Research also found that Ang II enhanced TLR4-mediated signaling in microglia, induced microglial activation, and increased the production of reactive oxygen species within the paraventricular nucleus. ${ }^{41,42}$ Moreover, Ang II was found to play a major role in microglia polarization toward a proinflammatory and classically activated (M1) phenotype. ${ }^{43}$ In the present study, we found another function of candesartan: inhibition of enhanced chemokine release from astrocytes. This function might partially explain its neuroprotective effects during optic neuritis. Our findings, together with those in the literature, ${ }^{13}$ suggest that candesartan inhibits inflammation in the CNS through multiple pathways during EAE. It would be interesting to determine whether the incidence in MS in people routinely taking ACE inhibitors or Ang II receptor antagonists is low.

$\mathrm{NF}-\kappa \mathrm{B}$ is a ubiquitous transcription factor that plays an important role in controlling the expression of genes involved in immunity, inflammation, cell proliferation, and cell apoptosis. ${ }^{44-46}$ In the present study, we found that TLR4 expression was up-regulated by the Ang II-NF- $\kappa \mathrm{B}$ pathway (Figure 7). Interestingly, a previous study reported that Ang II induced an increase in the activity of
Rho-associated protein kinase via the NF- $\kappa \mathrm{B}$ pathway. ${ }^{41}$ As reported previously, this pathway is particularly important in the migration of inflammatory cells, including microglia, to sites of inflammation. ${ }^{47,48}$ Additional studies are needed to elucidate details of the Ang II-NF- $\mathrm{B}$ pathway.
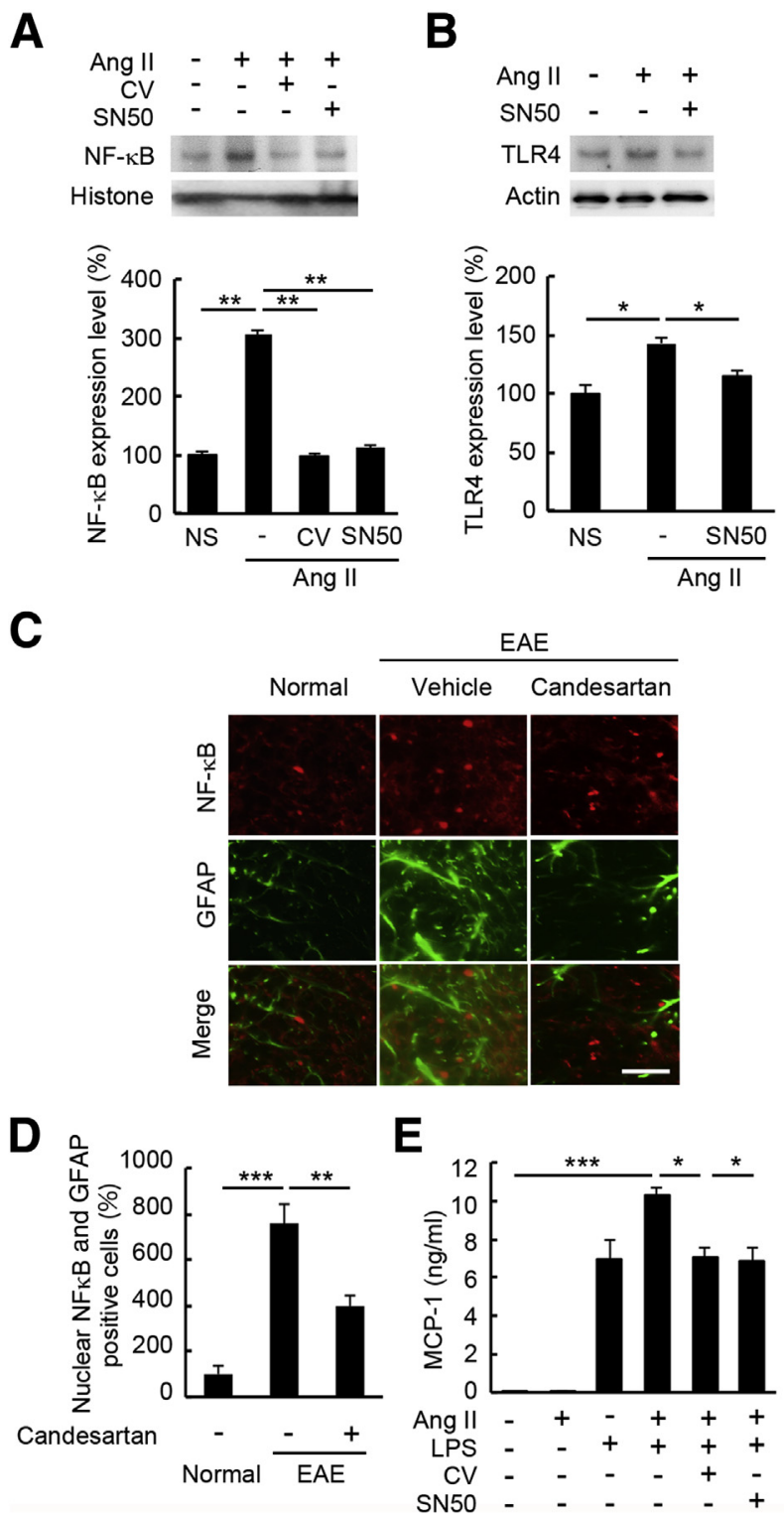

Figure 7 Candesartan suppressed the activation of astrocytes via NF$\kappa \mathrm{B}-$ Toll-like receptor (TLR)-4 signaling. A: Immunoblot analysis of NF- $\kappa \mathrm{B}$ in nuclear fractions of astrocytes treated with CV-11974 (CV) or SN50 for 45 minutes followed by stimulation with angiotensin II (Ang II) for 1 hour. B: Immunoblot analysis of TLR4 in astrocytes treated with SN50 for 45 minutes followed by Ang II stimulation for 24 hours. C: Immunohistochemistry using antibodies for NF- $\kappa B$ (red) and glial fibrillary acidic protein (GFAP) (green) in the spinal cord of mice with EAE with or without candesartan treatment. D: Quantitative analysis of NF- $\kappa B$ and GFAP doublepositive cells in panel C. E: Effects of CV and SN50 on the production of monocyte chemotactic protein (MCP)-1 in astrocytes pretreated with Ang II for 24 hours followed by lipopolysaccharide (LPS) stimulation for 24 hours. Data are expressed as means \pm SEM for a representative experiment run in quadruplicate (A, B and E); means \pm SEM (D). $n=4$ (D). ${ }^{\star} P<0.05$, ${ }^{*} P<0.01$, and ${ }^{* * *} P<0.001$. Scale bar $=40 \mu \mathrm{m}$ (C). 
However, this result of TLR4 up-regulation by the Ang II-NF- $\mathrm{B}$ pathway seems to be interesting because NF- $\kappa \mathrm{B}$ is also activated by TLR pathways and a variety of inflammatory signals, such as interleukin- $1 \beta$ and tumor necrosis factor- $\alpha .{ }^{38}$ These findings suggest that NF- $\kappa \mathrm{B}$ is involved in the pathogenesis of MS and EAE upstream and downstream of TLR signaling.

Other downstream molecules of TLR signaling pathways, such as myeloid differentiation factor 88 and apoptosis signal-regulating kinase (ASK)-1, are also important during EAE. ${ }^{22}$ Previous studies found that mice deficient in the TLR adaptor protein myeloid differentiation factor 88 were completely resistant to MOG-induced EAE. ${ }^{17,49}$ We recently found that genetic or pharmacologic depletion of ASK1, a mitogen-activated protein kinase kinase kinase that plays a pivotal role in reactive oxygen species-induced cellular responses, ${ }^{50-52}$ ameliorated the severity of EAE and attenuated visual impairment by disrupting the TLR4-ASK1-p38 mitogen-activated protein kinase pathway in astrocytes and microglial cells. ${ }^{18}$ Taken together, these results suggest that the Ang II-NF- $\kappa \mathrm{B}-\mathrm{TLR} 4-\mathrm{ASK} 1-\mathrm{p} 38$ and Ang II-NF$\kappa \mathrm{B}-\mathrm{TLR} 4-\mathrm{NF}-\kappa \mathrm{B}$ pathways are valid targets for the treatment of neuroinflammation. Recently, p38 has emerged as a potential therapeutic target for the treatment of various conditions, including Alzheimer disease, cardiac ischemia or reperfusion injury, and chronic airways disease. ${ }^{53-55} \mathrm{We}$ found that an intraocular injection of a p38 inhibitor protected RGCs after optic nerve injury. ${ }^{56}$ Because RGC loss is observed in the retina of mice with EAE (Figure 3), a p38 inhibitor, as well as an Ang II receptor antagonist, might be an effective treatment for optic neuritis. Our results suggest that combined inhibition of the RAS and innate immune system might be effective in reducing the incidence and severity of CNS autoimmune diseases.

In conclusion, we detected a novel association in astrocytes between the RAS and innate immune system in a mouse model of optic neuritis. Further efforts to discover new compounds that can specifically inhibit the RAS-NF- $\mathrm{B}-\mathrm{TLR} 4$ pathway for a prolonged period may lead to the development of novel strategies for the management of deteriorating inflammatory autoimmune and neurodegenerative diseases, including Alzheimer disease, Guillain-Barré syndrome, acute disseminated encephalomyelitis, and MS. ${ }^{57-59}$

\section{Acknowledgments}

We thank Mayumi Kunitomo, Keiko Okabe, and Sayaka Ihara for their technical assistance.

\section{References}

1. Guo X: Optic neuritis. Edited by Nakazawa T, Kitaoka Y, Harada T. In Neuroprotection and Neuroregeneration for Retinal Diseases. Tokyo: Springer, 2014, pp. 307-321
2. Petzold A, Wattjes MP, Costello F, Flores-Rivera J, Fraser CL, Fujihara K, Leavitt J, Marignier R, Paul F, Schippling S, Sindic C, Villoslada P, Weinshenker B, Plant GT: The investigation of acute optic neuritis: a review and proposed protocol. Nat Rev Neurol 2014, 10:447-458

3. Toosy AT, Mason DF, Miller DH: Optic neuritis. Lancet Neurol 2014, 13:83-99

4. Rodriguez M, Siva A, Cross SA, O’Brien PC, Kurland LT: Optic neuritis: a population-based study in Olmsted County, Minnesota. Neurology 1995, 45:244-250

5. Jarius S, Wildemann B, Paul F: Neuromyelitis optica: clinical features, immunopathogenesis and treatment. Clin Exp Immunol 2014, 176:149-164

6. Baker KM, Booz GW, Dostal DE: Cardiac actions of angiotensin II: role of an intracardiac renin-angiotensin system. Annu Rev Physiol 1992, 54:227-241

7. Goodfriend TL, Elliott ME, Catt KJ: Angiotensin receptors and their antagonists. N Engl J Med 1996, 334:1649-1654

8. Chobanian AV, Bakris GL, Black HR, Cushman WC, Green LA, Izzo JL Jr, Jones DW, Materson BJ, Oparil S, Wright JT Jr, Roccella EJ; National Heart, Lung, and Blood Institute Joint National Committee on Prevention, Detection, Evaluation, and Treatment of High Blood Pressure; National High Blood Pressure Education Program Coordinating Committee: The seventh report of the Joint National Committee on Prevention, Detection, Evaluation, and Treatment of High Blood Pressure: the JNC 7 report. JAMA 2003, 289:2560-2572

9. Constantinescu CS, Ventura E, Hilliard B, Rostami A: Effects of the angiotensin converting enzyme inhibitor captopril on experimental autoimmune encephalomyelitis. Immunopharmacol Immunotoxicol $1995,17: 471-491$

10. Stegbauer J, Lee DH, Seubert S, Ellrichmann G, Manzel A, Kvakan H, Muller DN, Gaupp S, Rump LC, Gold R, Linker RA: Role of the renin-angiotensin system in autoimmune inflammation of the central nervous system. Proc Natl Acad Sci U S A 2009, 106: 14942-14947

11. Platten M, Youssef S, Hur EM, Ho PP, Han MH, Lanz TV, Phillips LK, Goldstein MJ, Bhat R, Raine CS, Sobel RA, Steinman L: Blocking angiotensin-converting enzyme induces potent regulatory $\mathrm{T}$ cells and modulates TH1- and TH17-mediated autoimmunity. Proc Natl Acad Sci U S A 2009, 106:14948-14953

12. Constantinescu CS, Goodman DB, Grossman RI, Mannon LJ, Cohen JA: Serum angiotensin-converting enzyme in multiple sclerosis. Arch Neurol 1997, 54:1012-1015

13. Lanz TV, Ding Z, Ho PP, Luo J, Agrawal AN, Srinagesh H, Axtell R, Zhang H, Platten M, Wyss-Coray T, Steinman L: Angiotensin II sustains brain inflammation in mice via TGF-beta. J Clin Invest 2010, 120:2782-2794

14. Bsibsi M, Ravid R, Gveric D, van Noort JM: Broad expression of Toll-like receptors in the human central nervous system. J Neuropathol Exp Neurol 2002, 61:1013-1021

15. Zekki H, Feinstein DL, Rivest S: The clinical course of experimental autoimmune encephalomyelitis is associated with a profound and sustained transcriptional activation of the genes encoding toll-like receptor 2 and CD14 in the mouse CNS. Brain Pathol 2002, 12:308-319

16. Kerfoot SM, Long EM, Hickey MJ, Andonegui G, Lapointe BM, Zanardo RC, Bonder C, James WG, Robbins SM, Kubes P: TLR4 contributes to disease-inducing mechanisms resulting in central nervous system autoimmune disease. J Immunol 2004, 173:7070-7077

17. Prinz M, Garbe F, Schmidt H, Mildner A, Gutcher I, Wolter K, Piesche M, Schroers R, Weiss E, Kirschning CJ, Rochford CD, Bruck W, Becher B: Innate immunity mediated by TLR9 modulates pathogenicity in an animal model of multiple sclerosis. J Clin Invest 2006, 116:456-464

18. Guo X, Harada C, Namekata K, Matsuzawa A, Camps M, Ji H, Swinnen D, Jorand-Lebrun C, Muzerelle M, Vitte PA, Ruckle T, Kimura A, Kohyama K, Matsumoto Y, Ichijo H, Harada T: 
Regulation of the severity of neuroinflammation and demyelination by TLR-ASK1-p38 pathway. EMBO Mol Med 2010, 2:504-515

19. Racke MK, Hu W, Lovett-Racke AE: PTX cruiser: driving autoimmunity via TLR4. Trends Immunol 2005, 26:289-291

20. Hansen BS, Hussain RZ, Lovett-Racke AE, Thomas JA, Racke MK: Multiple toll-like receptor agonists act as potent adjuvants in the induction of autoimmunity. J Neuroimmunol 2006, 172:94-103

21. Wolf NA, Amouzegar TK, Swanborg RH: Synergistic interaction between Toll-like receptor agonists is required for induction of experimental autoimmune encephalomyelitis in Lewis rats. J Neuroimmunol 2007, 185:115-122

22. Ruggiero V: Involvement of IL-1R/TLR signalling in experimental autoimmune encephalomyelitis and multiple sclerosis. Curr Mol Med 2012, 12:218-236

23. Wolf G, Bohlender J, Bondeva T, Roger T, Thaiss F, Wenzel UO: Angiotensin II upregulates toll-like receptor 4 on mesangial cells. J Am Soc Nephrol 2006, 17:1585-1593

24. Semba K, Namekata K, Guo X, Harada C, Harada T, Mitamura Y: Renin-angiotensin system regulates neurodegeneration in a mouse model of normal tension glaucoma. Cell Death Dis 2014, 5: e1333

25. Shibouta Y, Inada Y, Ojima M, Wada T, Noda M, Sanada T, Kubo K, Kohara Y, Naka T, Nishikawa K: Pharmacological profile of a highly potent and long-acting angiotensin II receptor antagonist, 2-ethoxy-1[[2'-(1H-tetrazol-5-yl)biphenyl-4- yl]methyl]-1H-benzimidazole-7carboxylic acid (CV-11974), and its prodrug, (+/-)-1-(cyclohexyloxycarbonyloxy)-ethyl 2-ethoxy-1-[[2'-(1H-tetrazol-5- yl) biphenyl-4-yl]methyl]-1H-benzimidazole-7-carboxylate (TCV-116). J Pharmacol Exp Ther 1993, 266:114-120

26. Mendel I, Kerlero de Rosbo N, Ben-Nun A: A myelin oligodendrocyte glycoprotein peptide induces typical chronic experimental autoimmune encephalomyelitis in $\mathrm{H}-2 \mathrm{~b}$ mice: fine specificity and $\mathrm{T}$ cell receptor $\mathrm{V}$ beta expression of encephalitogenic $\mathrm{T}$ cells. Eur J Immunol 1995, 25:1951-1959

27. Guo X, Harada C, Namekata K, Mitamura Y, Yoshida H, Matsumoto Y, Harada T: Delayed onset of experimental autoimmune encephalomyelitis in Olig1 deficient mice. PLoS One 2010, 5: e13083

28. Guo X, Harada C, Namekata K, Kimura A, Mitamura Y, Yoshida H, Matsumoto Y, Harada T: Spermidine alleviates severity of murine experimental autoimmune encephalomyelitis. Invest Ophthalmol Vis Sci 2011, 52:2696-2703

29. Harada C, Nakamura K, Namekata K, Okumura A, Mitamura Y, lizuka Y, Kashiwagi K, Yoshida K, Ohno S, Matsuzawa A, Tanaka K, Ichijo H, Harada T: Role of apoptosis signal-regulating kinase 1 in stress-induced neural cell apoptosis in vivo. Am J Pathol 2006, 168:261-269

30. Alfonso-Loeches S, Pascual-Lucas M, Blanco AM, SanchezVera I, Guerri C: Pivotal role of TLR4 receptors in alcoholinduced neuroinflammation and brain damage. J Neurosci 2010, 30:8285-8295

31. Tseng PH, Matsuzawa A, Zhang W, Mino T, Vignali DA, Karin M: Different modes of ubiquitination of the adaptor TRAF3 selectively activate the expression of type I interferons and proinflammatory cytokines. Nat Immunol 2010, 11:70-75

32. Damgaard RB, Walker JA, Marco-Casanova P, Morgan NV, Titheradge HL, Elliott PR, McHale D, Maher ER, McKenzie AN, Komander D: The Deubiquitinase OTULIN is an essential negative regulator of inflammation and autoimmunity. Cell 2016, 166: 1215-1230.e20

33. Nakazawa S, Oikawa D, Ishii R, Ayaki T, Takahashi H, Takeda H, Ishitani R, Kamei K, Takeyoshi I, Kawakami H, Iwai K, Hatada I, Sawasaki T, Ito H, Nureki O, Tokunaga F: Linear ubiquitination is involved in the pathogenesis of optineurin-associated amyotrophic lateral sclerosis. Nat Commun 2016, 7:12547

34. Guo X, Nakamura K, Kohyama K, Harada C, Behanna HA, Watterson DM, Matsumoto Y, Harada T: Inhibition of glial cell activation ameliorates the severity of experimental autoimmune encephalomyelitis. Neurosci Res 2007, 59:457-466

35. Ozawa Y, Yuki K, Yamagishi R, Tsubota K, Aihara M: Reninangiotensin system involvement in the oxidative stress-induced neurodegeneration of cultured retinal ganglion cells. Jpn J Ophthalmol 2013, 57:126-132

36. Guo X, Namekata K, Kimura A, Noro T, Azuchi Y, Semba K, Harada C, Yoshida H, Mitamura Y, Harada T: Brimonidine suppresses loss of retinal neurons and visual function in a murine model of optic neuritis. Neurosci Lett 2015, 592:27-31

37. Harada C, Namekata K, Guo X, Yoshida H, Mitamura $Y$, Matsumoto Y, Tanaka K, Ichijo H, Harada T: ASK1 deficiency attenuates neural cell death in GLAST-deficient mice, a model of normal tension glaucoma. Cell Death Differ 2010, 17:1751-1759

38. Bonizzi G, Karin M: The two NF-kappaB activation pathways and their role in innate and adaptive immunity. Trends Immunol 2004, 25: $280-288$

39. Luo J, Ho PP, Buckwalter MS, Hsu T, Lee LY, Zhang H, Kim DK, Kim SJ, Gambhir SS, Steinman L, Wyss-Coray T: Glia-dependent TGF-beta signaling, acting independently of the TH17 pathway, is critical for initiation of murine autoimmune encephalomyelitis. J Clin Invest 2007, 117:3306-3315

40. Mishra MK, Yong VW: Myeloid cells - targets of medication in multiple sclerosis. Nat Rev Neurol 2016, 12:539-551

41. Rodriguez-Perez AI, Borrajo A, Rodriguez-Pallares J, Guerra MJ, Labandeira-Garcia JL: Interaction between NADPH-oxidase and Rho-kinase in angiotensin II-induced microglial activation. Glia 2015, 63:466-482

42. Biancardi VC, Stranahan AM, Krause EG, de Kloet AD, Stern JE: Cross talk between AT1 receptors and Toll-like receptor 4 in microglia contributes to angiotensin II-derived ROS production in the hypothalamic paraventricular nucleus. Am J Physiol Heart Circ Physiol 2016, 310:H404-H415

43. Labandeira-Garcia JL, Rodriguez-Perez AI, Garrido-Gil P, Rodriguez-Pallares J, Lanciego JL, Guerra MJ: Brain renin-angiotensin system and microglial polarization: implications for aging and neurodegeneration. Front Aging Neurosci 2017, 9:129

44. Hilliard BA, Mason N, Xu L, Sun J, Lamhamedi-Cherradi SE, Liou HC, Hunter C, Chen YH: Critical roles of c-Rel in autoimmune inflammation and helper T cell differentiation. J Clin Invest 2002, 110:843-850

45. van Loo G, De Lorenzi R, Schmidt H, Huth M, Mildner A, SchmidtSupprian M, Lassmann H, Prinz MR, Pasparakis M: Inhibition of transcription factor NF-kappaB in the central nervous system ameliorates autoimmune encephalomyelitis in mice. Nat Immunol 2006, 7:954-961

46. Hayden MS, Ghosh S: NF-kappaB in immunobiology. Cell Res 2011, 21:223-244

47. Greenwood J, Walters CE, Pryce G, Kanuga N, Beraud E, Baker D, Adamson P: Lovastatin inhibits brain endothelial cell Rho-mediated lymphocyte migration and attenuates experimental autoimmune encephalomyelitis. FASEB J 2003, 17:905-907

48. Honing H, van den Berg TK, van der Pol SM, Dijkstra CD, van der Kammen RA, Collard JG, de Vries HE: RhoA activation promotes transendothelial migration of monocytes via ROCK. J Leukoc Biol 2004, 75:523-528

49. Miranda-Hernandez S, Gerlach N, Fletcher JM, Biros E, Mack M, Korner H, Baxter AG: Role for MyD88, TLR2 and TLR9 but not TLR1, TLR4 or TLR6 in experimental autoimmune encephalomyelitis. J Immunol 2011, 187:791-804

50. Ichijo H, Nishida E, Irie K, ten Dijke P, Saitoh M, Moriguchi T, Takagi M, Matsumoto K, Miyazono K, Gotoh Y: Induction of apoptosis by ASK1, a mammalian MAPKKK that activates SAPK/JNK and p38 signaling pathways. Science 1997, 275: 90-94

51. Bjornsti MA, Houghton PJ: The TOR pathway: a target for cancer therapy. Nat Rev Cancer 2004, 4:335-348 
52. Hattori K, Naguro I, Runchel C, Ichijo H: The roles of ASK family proteins in stress responses and diseases. Cell Commun Signal 2009, $7: 9$

53. Munoz L, Ammit AJ: Targeting p38 MAPK pathway for the treatment of Alzheimer's disease. Neuropharmacology 2010, 58:561-568

54. Chung KF: p38 mitogen-activated protein kinase pathways in asthma and COPD. Chest 2011, 139:1470-1479

55. Kumphune S, Chattipakorn S, Chattipakorn N: Role of p38 inhibition in cardiac ischemia/reperfusion injury. Eur J Clin Pharmacol 2012, 68: 513-524
56. Katome T, Namekata K, Guo X, Semba K, Kittaka D, Kawamura K, Kimura A, Harada C, Ichijo H, Mitamura Y, Harada T: Inhibition of ASK1-p38 pathway prevents neural cell death following optic nerve injury. Cell Death Differ 2013, 20:270-280

57. Weiner HL, Selkoe DJ: Inflammation and therapeutic vaccination in CNS diseases. Nature 2002, 420:879-884

58. Steinman L: Nuanced roles of cytokines in three major human brain disorders. J Clin Invest 2008, 118:3557-3563

59. Kapadia M, Sakic B: Autoimmune and inflammatory mechanisms of CNS damage. Prog Neurobiol 2011, 95:301-333 